\title{
A Rare Cardiac Malformation in a Patient Presenting with Transient Ischemic Attack: Isolated Left Ventricular Diverticulum
}

\author{
Emir Karacağlar ${ }^{1}$ Tansel Erol², Haldun Müderrisoğlu \\ ${ }^{1}$ Department of Cardiology, Faculty of Medicine Hospital, Baskent University, Ankara, Turkey \\ ${ }^{2}$ Department of Cardiology, Faculty of Medicine Hospital, Baskent University, Adana, Turkey
}

\begin{abstract}
Left ventricular diverticulum is a rare congenital malformation consisting of a localized protrusion of the endocardium and myocardium from the free wall of the left ventricle (LV). The prevalence of the disease is $0.26 \%$ in nonselected patients who underwent cardiac catheterization. It is believed that the etiology is an intrinsic abnormality developing during embryogenesis. It often does not cause any symptoms. We report a case of isolated left ventricular diverticulum with complaints of transient ischemic attack.
\end{abstract}

Key Words: Left ventricular diverticulum, transient ischemic attack, venticulography

\section{Case Presentation}

A 66 year old male patient was admitted to our hospital with left arm weakness and speech disturbance. There was no prior cerebrovascular event in his medical history. His electrocardiogram (ECG) was normal. No abnormalities were detected in cranial computed tomography, magnetic resonance imaging, and carotid artery doppler imaging. The patient was diagnosed with transient ischemic attack (TIA). No rhythm abnormalities such as atrial fibrillation were detected during hospitalization. His complaints resolved completely with appropriate antiplatelet and anticoagulant therapy. After one week the patient complained of chest pain. New anterolateral T wave inversions were detected on his ECG. Serial troponin measurements were within normal range. Echocardiographic (ECHO) examination revealed normal findings. The patient underwent coronary angiography. The patient's coronary arteries were normal but left ventriculography revealed a diverticulum at the apex of the left ventricle (Figure 1, Video 1).

\section{Results}

Our patient's clinical manifestation may not be associated with diverticulum and may be diagnosed incidentally, but there was no other underlying reason that may cause TIA. There were no thrombi in the sac but the patient was already under appropriate antiplatelet and anticoagulant therapy. The patient was treated successfully with oral anticoagulant therapy.

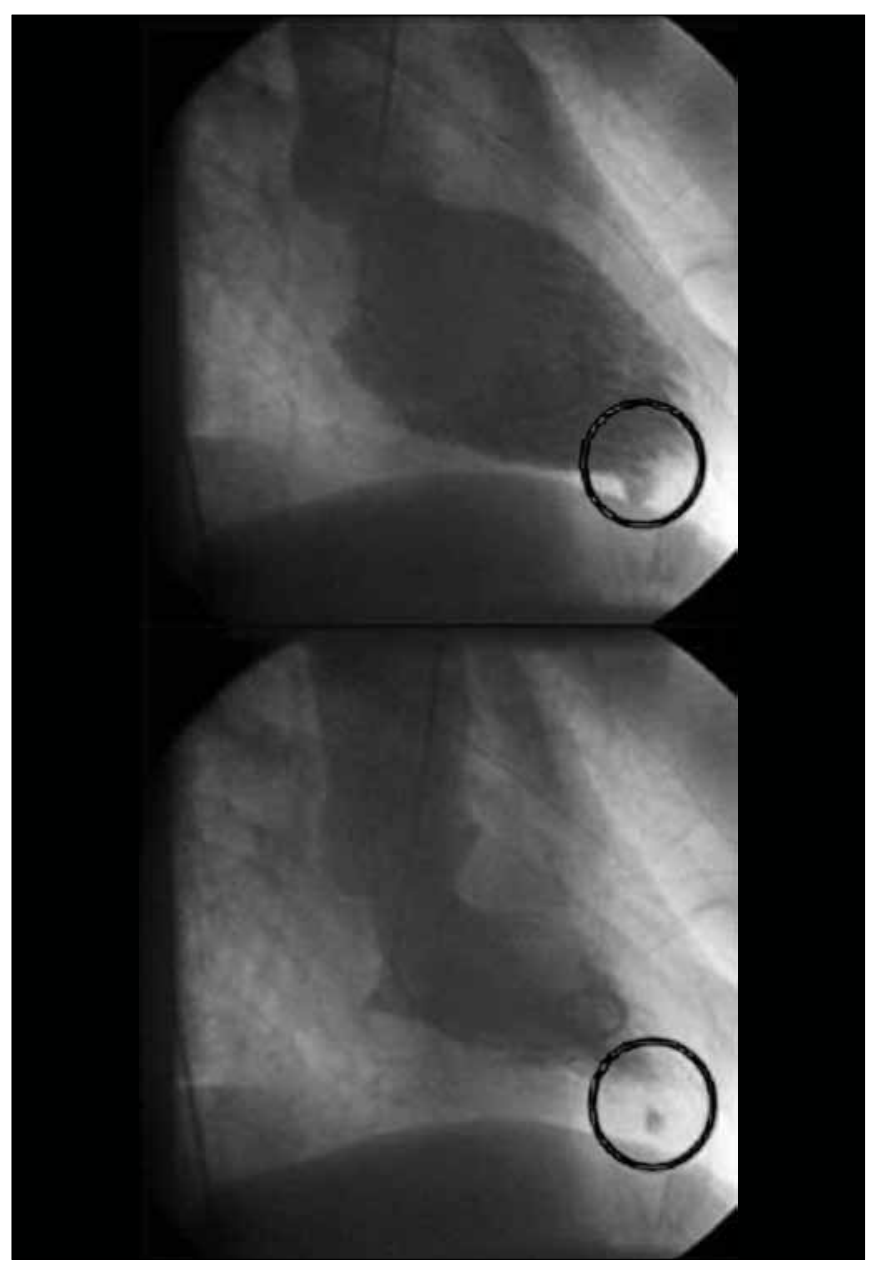




\section{Reason of Case Presentation}

The unusual aspect of this case is that there were no other abnormalities which could have caused TIA except for diverticulum in an elderly patient. Echocardiography is useful for showing a diverticulum, but it is difficult to detect small ones by the conventional 2-D method. In our case, ECHO was normal and the diverticulum was very small to detect. Angiographic ventriculography is the gold standard for diagnosing the diverticulum (1). We wish to emphasize the importance of left ven- triculography in patients with chest pain and embolism, even in patients with normal echocardiographic findings and normal coronary arteries in order to diagnose diverticulum.

\section{References}

1. Ghersin E, Kerner A, Gruberg L, Bar-El Y, Abadi S, Engel A. Left ventricular pseudoaneurysm or diverticulum: differential diagnosis and dynamic evaluation by catheter left ventriculography and ECG-gated multidetector CT. Br J Radiol 2007;80:e209-11. [CrossRef]

\section{Book Announcement}

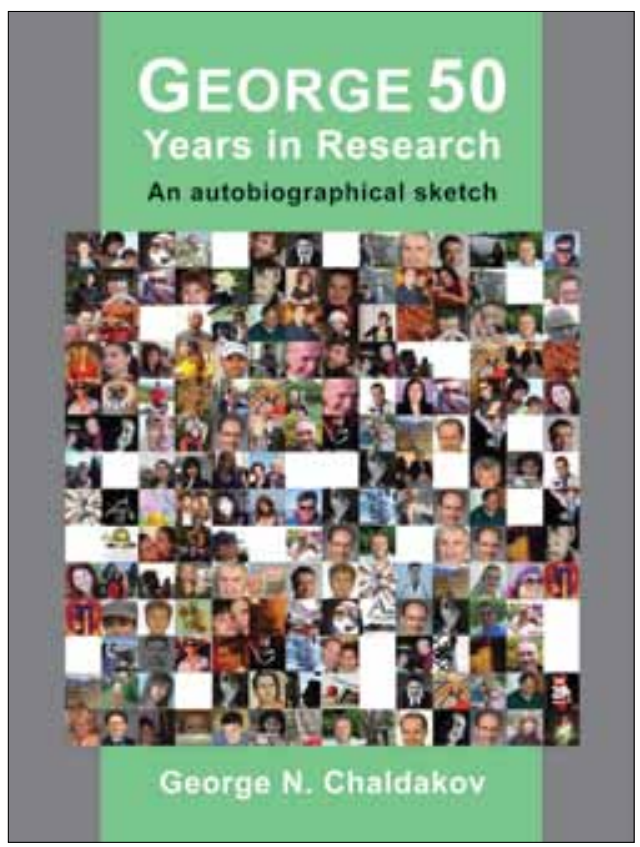

George N. Chaldakov. George 50 Years in Research. An autobiographical sketch (ISBN 978-954-8493-30-7) MS Publishing Ltd, Varna, Bulgaria, 2012.

We are honored to announce the book of George Chaldakov, who is one of our distinguished members of the International Editorial Board.

\section{Cem Uzun}

"George Chaldakov, one of the most prominent scientists of Bulgaria, is celebrating his 50 years in research. His philosophy states that studying hard with sleepless nights in lab may promote science, but if we add friendship to all these efforts, then we can succeed unbelievable improvements and make priceless contributions to both science and our lives. The book entitled "George 50 Years in Research. An autobiographical sketch" tells the story of such a great success."

\section{Levent Öztürk}

"...The memories of parents, teachers, colleague-friends. And the native Burgas - genius loci (spirit of a place), numen inest (there is a spirit here). Arguably, George 50 is more biographical sketch of my circumstance rather than a biography of I am."

\section{George N. Chaldakov}

